\title{
Better Safe than Sorry: Risking Irresponsibility by Seeking Uncertainty
}

\author{
Gro Hege Haraldsen Nordbye ${ }^{1}$, Anine Riege ${ }^{1,2}$ and Karl Halvor Teigen ${ }^{1,3}$ \\ ${ }^{1}$ Department of Psychology, University of Oslo, Oslo \\ ${ }^{2}$ Kingston Business School, Kingston University, London, UK \\ ${ }^{3}$ Simula Research Laboratory, Oslo, Norway
}

Correspondence to: Anine H. Riege, Kingston Business School, Kingston Hill, Kingston upon Thames KT2 7LB, Kingston University London, UK. E- mail: a.riege@ kingston.ac.uk

\begin{abstract}
Research findings differ as to whether choosing a risky option is an efficient strategy for decision makers seeking to avoid responsibility for potential failures. A risky choice may leave the final outcome to chance factors, but the decision maker can still be held responsible for choosing risk. Further, it is unclear whether a risky choice is a responsible choice. The present article investigates the putative relationship between risk- taking and responsibility by drawing a distinction between being responsible for the outcome (R1) versus acting responsibly (R2). Four experiments were performed, in which participants were presented with scenarios describing decision makers facing a choice between a risky (uncertain) option and a riskless (certain) option, framed in terms of losses or equivalent gains. The results showed that decision makers who chose the risky alternative were judged to have acted in a less responsible manner (R2), while still being held equally responsible for the outcome (R1), unless they were ignorant of the risks involved. Choosing risk did not absolve decision makers from blame, despite being less causal and less in control than those who chose the riskless option. Risky decision makers were also judged to be more personally involved. The dissociation between R1 and R2 ratings confirms earlier findings and serves to clarify an alleged relationship between risky choices and responsibility aversion. Framing effects for own choices were found in both scenarios. In contrast, responsibility ratings were only slightly affected by frame. Copyright (C) 2017 John Wiley \& Sons, Ltd.
\end{abstract}


In a variety of professional roles, and in their private lives, people find themselves in situations in which at least one of their options is fraught with uncertainty. For example, should a private equity broker invest the client's money in a fluctuating stock market with possible high gains, but also potential high losses, or keep the money in a low- risk, lowyield fund? Should the health authorities in Tversky and Kahneman's (1981) famous Asian Disease (AD) problem choose the "certain outcome" program, saving 200 lives for sure, or the "risky" program, where best case could save all 600, but in the worst case save none? The present paper investigates how people judge the decision maker's responsibility in choices between risky options and certain options. We do so by drawing a distinction between being personally responsible for the outcome (R1) versus acting responsibly (R2).

\section{Responsible for Outcome versus Acting Responsibly}

Debates about responsibility are not limited to assessing the causal contributions of the actors involved and who should be praised or blamed for more or less successful outcomes, but also include whether a decision maker has acted in a morally responsible way. We claim that such moral judgments are central for allocating responsibility, although largely overlooked in attribution research. Nordbye and Teigen (2014a) distinguished between two central aspects of the responsibility concept: R1 - being personally responsible for a decision or its consequences, and R2 - acting responsibly. The R1 sense of responsibility is related to the causal and the classical attribution way of looking at responsibility, or in other words, being personally responsible for the outcome. Acting responsibly (R2), on the other hand, reflects cultural expectancies, morality, duties, and obligations and is linked to social and professional roles (Cane, 2002; Hamilton \& Hagiwara, 1992; Hart, 2008; Vincent, 2011). A highly responsible decision maker is assumed to perform careful, well- balanced decisions, without inflicting avoidable harm, which is a general value in our society. Social value theory states that the social value of risk (or rather to avoid risk) is a major determinant of decisions we make for others (Stone, Choi, de Bruin, \& Mandel, 2013) and could also guide the moral evaluation of the decision maker in risky choice dilemmas. Risky decisions involve, by definition, a venture into the unknown with less control over the outcomes, including potentially damaging ones, which could be incompatible with acting in a responsible way. Nordbye and Teigen (2014a, Exp.2) accordingly found that high risk- takers were viewed as acting in a less responsible manner than low risk- takers (R2). They were at the same time deemed as having higher outcome responsibility (R1). However, the risks in these previous studies were not quantified in terms of probabilities and expected outcomes. Hence, it remains to be seen if risk- takers are still judged as behaving less responsibly (R2) while carrying more outcome responsibility (R1) in cases where the expected utilities of both decisions can be compared. Decisions between certain and risky options have been shown to be influenced by framing, where people usually prefer the certain option in a save frame and prefer the risky option in the loss frame (Tversky \& Kahneman, 1981). The present paper will therefore investigate responsibility judgments within both frames, though the main aim is to compare the effect of risky and riskless choices (regardless of frame) upon R1 and R2 judgments.

\section{Responsibility and Risk}

It has recently been argued that decision makers may choose an uncertain option, not because of loss aversion, as suggested by prospect theory (Kahneman \& Tversky, 1979), but because of responsibility aversion (Leonhardt, Keller, \& Pechmann, 2011; Tykocinski, Amir, \& Ayal, $\underline{2016)}$. 
To be fully responsible for an event, a person needs to have caused the event to happen, been in control of the outcome, been able to foresee the consequences, and have had an intention of the outcome to happen (Alicke, 2000; Lagnado \& Channon, 2008; Malle, Guglielmo, \& Monroe, 2014; Shaver, 1985). It follows that an actor carries more responsibility the more he or she can be seen as an active contributor to the results (Cane, 2002; Chockler \& Halpern, 2004; Lagnado, Gerstenberg, \& Zultan, 2013; Weiner, 1995). Conversely, the more situational (external) determinants for the action, the less the actor can be held responsible. In line with this, Leonhardt et al. (2011) proposed that risk- seeking behavior could be a strategy for evading responsibility. In several experiments, the first of them using the AD paradigm, participants were asked how they would feel about the outcomes of a certain or an uncertain option. The results indicated that participants felt less accountable, less guilty, and less blameworthy for the uncertain (risky) options, perhaps because these involved an intervention of chance factors or other agents with which one could share the responsibility. In a more recent set of studies, Tykocinski et al. (2016) found risky choice framing effects only in situations where the actors were perceived to be highly responsible. They argue that such actors want to reduce their responsibility for losses but not for gains, which makes them prefer the "risky" option in a loss frame. By allowing chance factors to play a role in generating the final outcome, the actor appears less blameworthy, according to this account. Thus, the preference for the risky option may be seen as an impression management strategy to attenuate responsibility and blame.

However, other research has shown that people are often reluctant to accept randomizers (e.g., coin- flipping) as a decision aid, even in choices between equivalent options, partly because it is perceived as an improper evasion of responsibility (Keren \& Teigen, 2010). Nordbye and Teigen (2014a) found that risk- taking actors were considered more responsible for their decisions than actors choosing alternatives with less risk. Moreover, if a risk- taking actor could have made a different decision (namely, chosen the riskless alternative), he or she can be held responsible for making the risky choice itself, if not for its actual consequences. Such an actor could be made responsible for leaving the outcome to chance, and being blamed for behaving in a negligent way.

\section{The Present Studies}

The aim of the present studies was to investigate assessments of R1 and R2 for risk- averse and risk- seeking decision makers. Leonhardt et al. (2011) and Tykocinski et al. (2016) suggested that choice of the risky (uncertain) alternative reduces responsibility; however, these authors did not distinguish between outcome responsibility (R1) and behaving in a responsible way (R2). Moreover, Leonhardt et al. (2011) did not examine framing effects, as they only asked about feelings and uncertainty preferences in a loss frame where most people prefer the risky option. Tykocinski et al. (2016) studied the effects of high and low imagined responsibility on risky choice, rather than the other way around. Thus, personal responsibility was in their studies introduced as an independent variable rather than a consequence of choosing the risky or the riskless option. In contrast, we designed the present studies to examine how risky and riskless choices affect judgments of responsibility, both for losses and for gains. Further, we believe that knowledge of potential consequences (which are available even for the risky option) will give decision makers outcome responsibility, even for outcomes that are uncontrollable and not intended, when the risky choice is an informed and deliberate choice. We thus predicted that choosing the risky alternative will not excuse the decision maker from outcome responsibility (R1) when consequences are known. Moreover, if risk- taking is not considered the proper thing to do (Nordbye \& Teigen, 2014a), we 
expected that selecting the risky option would be considered a less responsible choice (R2) than selecting the "certain" option. We accordingly predict R1 and R2 ratings to diverge.

The R1-R2 distinction is further elaborated by assessing the relationship between R1 judgments with judgments of agency, operationalized as ratings of involvement (Experiments 1 and 2) and ratings of causal contribution (Experiments 3 and 4). R2 judgments are related to judgments of morality, operationalized as ratings of acceptability (measured in Experiments 3 and 4) and (inversely) as ratings of blameworthiness (measured in Experiments 1, 2, and 3). As our hypotheses diverge from those proposed by Leonhardt et al. (2011) and Tykocinski et al. (2016), we deemed that several mutually consistent studies would be needed to establish an alternative interpretation of the role of responsibility in risky choice.

Participants in all experiments were told about one decision maker who preferred the certain option and another who preferred the risky choice. Experiment 1 used a vaccination scenario involving saving versus losing lives. One group made R1 judgments and another group made R2 judgments, to avoid the two questions being answered differently for pragmatic reasons (Schwarz, 1999). To increase the generality of the results, Experiment 2 described a financial scenario, as some studies have found weaker framing effects for financial problems (Druckman \& McDermott, 2008; Fagley \& Miller, 1997; Kühberger, Schulte- Mecklenbeck, \& Perner, 1999; Wang, 1996). As responsibility judgments can be influenced in hindsight by outcome quality and outcome severity (Mazzocco, Alicke, \& Davis, 2004; Robbennolt, 2000; Walster, 1966), Experiment 2 explored three outcome conditions: no outcome, positive outcome, or negative outcome. Experiment 3 included both scenarios (within- Ss), allowing for direct comparisons between responsibility judgments in both domains. We predict that life and death situations will lead to more risk- seeking choices, but that this preference might not reduce responsibility ratings. In Experiment 4, we investigated the difference between informed and uninformed decision makers, where the latter run the same risks without deliberately choosing them. This comparison might reveal whether outcome responsibility can be reduced more by risk ignorance (uninformed decisions) than by risk- taking (informed decisions).

Thus, all experiments can be regarded as variations over the same theme, similar enough to serve as replication studies, and yet with differences that control for potential effects of design, scenarios, and rating scales, to establish the robustness of the main findings.

\section{Experiment 1: Saving and Losing Lives}

Experiment 1 used a risky choice scenario modeled after Tversky and Kahneman's (1981) original AD framing experiment, except that the 200 and 400 lives at peril belonged to two different risk groups, to make sure that "200 lives lost" or "400 lives saved" would not be interpreted as "200 [400] and perhaps more" (Kühberger, 1995; Mandel, 2014, 2015). One condition was positively framed in terms of lives saved, the other negatively framed in terms of lives lost. Participants were told about different choices made by the health authorities in two hypothetical countries and asked to either evaluate how responsible the decision makers were for the outcomes ( $\mathrm{R} 1$ ratings) or how responsibly they had acted ( $\mathrm{R} 2$ ratings). We expected that the decision maker who preferred the certain option would be regarded as acting in a more responsible way (R2), without being regarded as more responsible (R1) for the outcome.

\section{Method}




\section{Participants and design}

A total of 148 undergraduate students from the University of Troms $\varnothing$, Norway, participated in the study (77.7\% women, median age 21 years). Participation was voluntary and unpaid. Participants were randomly assigned to one of four conditions, according to a $2 \times 2$ betweensubjects design, with framing (lives saved versus lost) and type of responsibility (R1 versus $\mathrm{R} 2$ ratings) as the two factors.

\section{Procedure and material}

All participants received the following vaccination scenario in either the save or loss frame:

Imagine that two equally large countries are preparing for a new outburst of swine flu. This time two types of the virus exist: H1N1 and H1N2. Of these, H1N2 is more dangerous and is expected to kill 400 people, while H1N1 is expected to kill 200 people. The health authorities have a choice between to vaccines.

Vaccine A has an effect on H1N1, but not on H1N2. With this vaccination program 200 [400] people will be saved [die].

Vaccine $\mathrm{B}$ has a $1 / 3$ probability to have an effect on both viruses. With this vaccination program there is a $1 / 3$ chance of saving 600 people [no one will die], and a $2 / 3$ chance that no one [600] will be saved [die].

Then, participants were asked which of the options they preferred. They were then told about the ministers of health in the two countries, one of which chose vaccination program $A$ and the other vaccination program B. Subsequently, half of them were asked to rate both ministers of health for outcome responsibility (R1 ratings), whereas the other half rated which of the two ministers of health that had acted in the most responsible way (R2 ratings). Finally, all participants rated how personally involved and how blameworthy the two actors appeared to be. All ratings were performed on scales from 1 to 7 .

\section{Results}

\section{Preferences}

Personal preferences were affected by frame, indicative of the framing manipulation being successful. In the positively framed "lives saved" condition, $53 \%$ preferred the certain option, whereas in the "lives lost" frame, the certain option was chosen by only $25 \%, \chi^{2}(1$, $N=147)=10.52, p<.001$.

\section{Responsibility (R1) and involvement}

Decision makers choosing the risky and the certain option were rated about equally responsible for the outcome, as indicated by the $\mathrm{R} 1$ ratings in Table 1 . A mixed ANOVA of involvement ratings showed that the risk- taking minister was viewed as more personally involved than his risk- averse colleague, $F(1,145)=16.13, p<.001, \eta_{\mathrm{p}}{ }^{2}=.10$, but there was no interaction between frame and choice, $F(1,145)=1.31, p=.254, \eta_{\mathrm{p}}{ }^{2}=.009$. There were positive correlations between R1 judgments and involvement, which reached significance for 
the risky option, $r(60)=0.35, p=0.006$, but not for the certain option, $r(59)=0.25$, $p=0.055$.

Table 1. Mean ratings (SD) for certain and risky options in four conditions of the vaccination scenario, Experiment 1

Condition 1 (R1)

\section{Positive frame Negative frame}

\section{Certain Risky Certain Risky}

Responsibility 1
(SD)

Involvement

(SD)

Responsibility 2 (SD)

Blame (SD)
(1.75)

\subsection{0}

4.90

(1.25)

$5.17^{*}$

(1.37)
4.35

(1.33)
4.65

(1.36)

Condition 2 (R2)

Positive frame Negative frame Certain Risky Certain Risky

4.74

(1.53)

\subsection{8}

(1.58)

3.84

(1.60)

$4.98 * *$

(1.41) (1.41) (1.32)

- $* p<.05$.

- $\quad * * p<.01$ ( $t$ - tests for paired samples, comparing ratings of certain versus riskseeking decision makers).

\section{Responsible behavior (R2) and blame}

The risk- taking minister of health was viewed as making a less responsible (R2) decision. A $2 \times 2 \times 2$ mixed ANOVA with frame (save versus loss), own preference (certain versus risky), and choice of the two health ministers (certain versus risky) on $\mathrm{R} 2$ ratings showed a main effect of choice, $F(1,82)=16.64, p<.001, \eta_{\mathrm{p}}{ }^{2}=.17$. There was also a significant interaction between own preference and the health minister's choice, $F(1,62.34)=38.33, p<.001$, $\eta_{\mathrm{p}}{ }^{2}=.32$. The effect of own preference on $\mathrm{R} 2$ ratings is mainly driven by participants preferring the certain option and deeming the risky option to be particularly irresponsible $\left(M_{\text {certain }}=5.44\right.$ vs $\left.M_{\text {risky }}=3.16, t(31)=7.55, p<.001, d=1.34\right)$. Participants preferring the risky option rated the two options more similarly $\left(M_{\text {certain }}=4.21\right.$ vs $M_{\text {risky }}=4.68$, $t(53)=-1.86, p=.069, d=-0.25)$.

The expected negative correlations were found for $\mathrm{R} 2$ and blameworthiness, but again, it was only significant for the risky option, $r(84)=-0.39, p<0.001$, not for the certain option, $r(84)=-0.20, p=0.063$. Participants who themselves preferred the certain option deemed the risky option to be particularly blameworthy, and vice versa, $F(1,144)=17.87, p<.001$, $\eta_{\mathrm{p}}^{2}=.11$.

\section{Discussion}

Decision makers choosing the certain option were, as expected, perceived as acting in a more responsible way. Thus, R2 judgments reflect people's ideas of "doing the right thing" (Anderson, 1995). This was particularly true for those who themselves preferred the certain option, who deemed the risky choice both more irresponsible and blameworthy. Despite 
leaving more of the outcome to chance, risk- seeking decision makers were viewed as more personally involved, possibly reflecting a heightened sense of agency by making a norm violating choice (Kirkebøen \& Nordbye, 2015; Nichols, 2002). Perhaps because of these apparently conflicting features, decision makers who favored the risky options were not seen as less personally responsible (R1) for the outcome than their risk- averse colleagues. In the positive frame (not studied by Leonhardt et al., 2011), they were seen to have acted in a less responsible (R2) way.

\section{Experiment 2: Saving and Losing Money}

Experiment 2 explored within- Ss ratings of R1 and R2 in a financial context (adapted from Teigen \& Nikolaisen, 2009). Leonhardt et al. (2011) used a framing task without disclosing the outcome of the risky choice. Participants may therefore have believed that the outcome of the risky choice was positive and that no one died. Responsibility judgments in real life are often performed retrospectively, after the outcome is known. Prior studies of post- outcome responsibility have found responsibility judgments to be influenced in hindsight by outcome quality and outcome severity. When the consequences are more severe, responsibility increases (Robbennolt, 2000; Walster, 1966). Negative outcomes make the actor appear more blameworthy (Mazzocco et al., 2004). Participants in Experiment 2 were asked to make their evaluations either in a pre- outcome condition or in one successful and one unsuccessful post- outcome condition.

\section{Method}

\section{Participants}

A total of 207 undergraduate students at the University of Oslo participated (68\% women, median age 22 years) voluntary and unpaid. Participants were assigned to one of six conditions following a $2 \times 3$ design, with framing (money saved versus money lost) and outcome (no outcome versus positive versus negative outcome) as a between- Ss factor.

\section{Material and procedure}

All participants received the following scenario, with the strategies described in either a save or loss framed version.

Imagine that Per and Paul have each invested NOK 600,000 $(\$ 100,000)$ in a company that is now threatened by bankruptcy. Both Per's and Paul's investments include a large shareholding of NOK 400,000 and a smaller shareholding of NOK 200,000. A financial advisor concludes that there are two possible ways of handling the situation.

Strategy A: This strategy entails saving [losing] the smaller shareholding (save NOK 200,000 for sure [lose NOK 400,000]).

Strategy B: This strategy gives $1 / 3$ chance of saving both shareholdings [no loss] (save [not lose] NOK 600,000) and 2/3 chance of not saving anything [losing both shareholdings]. $\underline{-1}$ 
Participants in the pre- outcome (no outcome) condition were asked which strategy they themselves would have chosen. They were then told that one of the actors (Per) chose the certain outcome option and the other (Paul) the uncertain option and asked to rate on 1-7 rating scales, for each actor, how responsible are the two actors for the outcome (R1 ratings), how personally involved do you believe they feel, how responsibly did they act (R2 ratings), and how blameworthy they were for their actions.

Participants in the post- outcome conditions were not asked which option they favored (this would make little sense after the outcomes were disclosed). Instead they were informed about the outcomes of Per and Paul's choices. The risk- taking decision maker was successful in the positive outcome condition and failed in the negative outcome condition, whereas Per achieved the expected outcome in both conditions. Subsequently, both actors were rated for responsibility (R1 and R2), involvement, and blameworthiness, as in the no- outcome condition.

\section{Results}

\section{Preferences}

In the pre- outcome conditions, $77.1 \%$ preferred the certain choice in the save frame, compared $55.6 \%$ in the loss frame, $\chi^{2}(1, N=71)=3.70, p=.055$. Thus, strategy preferences were again influenced by the way the options are framed, but both groups were more riskaverse than in the life and death scenario of Experiment 1.

\section{Responsibility (R1) and involvement}

Participants in the pre- outcome condition gave the risk- taker higher outcome responsibility. A $2 \times 2 \times 2$ mixed ANOVA on R1 ratings, using frame (save versus loss), and outcome (no outcome versus known outcome) as between- Ss factors, and choice (certain versus risky) as a within- Ss factor, showed a main effect outcome, $F(1,200)=5.48, p<.020, \eta_{\mathrm{p}}{ }^{2}=.027$. After outcomes were known, the risk- taker was judged as less responsible for the outcome for both positive and negative outcomes, regardless of how they were framed. The risktaking investor also appeared to be more personally involved, $F(1,198)=52.4, p<.001$, $\eta_{\mathrm{p}}^{2}=.21$, regardless of outcome and framing.

\section{Responsible behavior (R2) and blame}

As seen in Table 2 , the risk- taker is judged to act less responsibly (R2), regardless of frame and in all three outcome conditions. A $2 \times 2 \times 3$ mixed ANOVA on R2 ratings, using frame (save versus loss), choice (certain versus risky), and outcome (no outcome versus positive outcome versus negative outcome), showed only a main effect of choice, $F(1,200)=284.4$, $p<.001, \eta_{\mathrm{p}}^{2}=.587$. However, as in Experiment 1, there was an effect of participants' own preferences on $\mathrm{R} 2$ ratings. Those that preferred the certain option deemed the risky option to be particularly irresponsible $\left(M_{\text {certain }}=5.91\right.$ vs $\left.M_{\text {risky }}=3.74, t(46)=10.84, p<.001, d=1.6\right)$. Participants who chose the risky option differed much less in their R2 ratings of the two options $\left(M_{\text {certain }}=5.26\right.$ vs $\left.M_{\text {risky }}=4.74, t(22)=1.55, p=.137, d=0.32\right)$. The risk- taking protagonist was deemed more blameworthy, $F(1,197)=52.14, p<.001, \eta_{\mathrm{p}}^{2}=.209$, regardless of the outcome and frame. 
Table 2. Mean ratings (SD) for certain and risky options in three outcome conditions of positively and negatively framed versions of the finance scenario, Experiment 2

\begin{tabular}{|c|c|c|c|c|c|c|}
\hline \multirow{2}{*}{ Ratings } & \multicolumn{3}{|c|}{ Positive frame } & \multicolumn{3}{|c|}{ Negative frame } \\
\hline & Certain & Risky & $t$ & Certain & Risky & $t$ \\
\hline \multicolumn{7}{|l|}{ Pre- outcome condition } \\
\hline Responsibility 1(SD) & $\begin{array}{l}5.00 \\
(1.79)\end{array}$ & $\begin{array}{l}5.56 \\
(1.28)\end{array}$ & -1.46 & $\begin{array}{l}4.68 \\
(1.68)\end{array}$ & $\begin{array}{l}5.24 \\
(1.44)\end{array}$ & - 2.14* \\
\hline Involvement (SD) & $\begin{array}{l}4.64 \\
(1.43)\end{array}$ & $\begin{array}{l}6.24 \\
(0.97)\end{array}$ & $5.45 * * *$ & $\begin{array}{l}4.68 \\
(1.32)\end{array}$ & $\begin{array}{l}5.80 \\
(1.45)\end{array}$ & -3.10 ** \\
\hline Responsibility 2 (SD) & $\begin{array}{l}5.82 \\
(1.09)\end{array}$ & $\begin{array}{l}4.09 \\
(1.33)\end{array}$ & $5.74 * * *$ & $\begin{array}{l}5.58 \\
(1.16)\end{array}$ & $\begin{array}{l}4.06 \\
(1.22)\end{array}$ & $5.95 * * *$ \\
\hline Blameworthy (SD) & $\begin{array}{l}2.45 \\
(1.46)\end{array}$ & $\begin{array}{l}3.90 \\
(1.94)\end{array}$ & $4.90 * * *$ & $\begin{array}{l}3.17 \\
(1.68)\end{array}$ & $\begin{array}{l}4.17 \\
(1.63)\end{array}$ & $3.30 * * *$ \\
\hline \multicolumn{7}{|c|}{$\begin{array}{l}\text { Post- outcome } \\
\text { conditions }\end{array}$} \\
\hline \multicolumn{7}{|c|}{ Positive outcome of risky program } \\
\hline Responsibility 1 (SD) & $\begin{array}{l}4.53 \\
(1.78)\end{array}$ & $\begin{array}{l}4.82 \\
(1.93)\end{array}$ & -0.85 & $\begin{array}{l}4.79 \\
(1.85)\end{array}$ & $\begin{array}{l}3.85 \\
(1.80)\end{array}$ & $2.77 * *$ \\
\hline Involvement(SD) & $\begin{array}{l}5.03 \\
(1.24)\end{array}$ & $\begin{array}{l}5.97 \\
(1.11)\end{array}$ & $-3.09 * *$ & $\begin{array}{l}4.82 \\
(1.45)\end{array}$ & $\begin{array}{l}5.55 \\
(1.33)\end{array}$ & -1.80 \\
\hline Responsibility 2(SD) & $\begin{array}{l}5.94 \\
(0.74)\end{array}$ & $\begin{array}{l}3.71 \\
(1.17)\end{array}$ & $8.70 * * *$ & $\begin{array}{l}5.45 \\
(1.06)\end{array}$ & $\begin{array}{l}3.94 \\
(1.30)\end{array}$ & 6.57 **** \\
\hline Blameworthy (SD) & $\begin{array}{l}2.88 \\
(1.79)\end{array}$ & $\begin{array}{l}4.03 \\
(1.77)\end{array}$ & -3.07 ** & $\begin{array}{l}3.36 \\
(1.73)\end{array}$ & $\begin{array}{l}3.55 \\
(1.77)\end{array}$ & -0.67 \\
\hline \multicolumn{7}{|c|}{ Negative outcome of risky program } \\
\hline Responsibility 1(SD) & $\begin{array}{l}5.03 \\
(1.92)\end{array}$ & $\begin{array}{l}4.74 \\
(1.96)\end{array}$ & 0.69 & $\begin{array}{l}4.44 \\
(2.03)\end{array}$ & $\begin{array}{l}4.76 \\
(1.58)\end{array}$ & -0.86 \\
\hline Involvement (SD) & $\begin{array}{l}4.71 \\
(1.51)\end{array}$ & $\begin{array}{l}5.74 \\
(1.04)\end{array}$ & -3.25 ** & $\begin{array}{l}4.71 \\
(1.17)\end{array}$ & $\begin{array}{l}5.44 \\
(1.52)\end{array}$ & -1.90 \\
\hline Responsibility 2 (SD) & $\begin{array}{l}5.97 \\
(0.92)\end{array}$ & $\begin{array}{l}3.77 \\
(1.17)\end{array}$ & $8.85 * * *$ & $\begin{array}{l}5.65 \\
(0.98)\end{array}$ & $\begin{array}{l}3.65 \\
(1.35)\end{array}$ & $6.22 * * *$ \\
\hline Blameworthy(SD) & $\begin{array}{l}3.11 \\
(1.51)\end{array}$ & $\begin{array}{l}4.20 \\
(1.64)\end{array}$ & $-2.95 * *$ & $\begin{array}{l}3.15 \\
(1.76)\end{array}$ & $\begin{array}{l}4.15 \\
(1.52)\end{array}$ & - 2.87 *** \\
\hline
\end{tabular}

\section{Discussion}

Decision makers who choose the risky strategy were in both frames considered more, rather than less responsible for the outcome, as long as the actual outcome remained unknown, but not in the post- outcome conditions. It is reasonable to claim that a decision maker should not receive full credit for a "lucky" success (Zimmermann, 1987). Similarly, accidental failures may reduce responsibility by being unintended (Lagnado \& Channon, 2008). 
Outcome responsibility (R1) does not entail acting in a responsible way (R2). These two concepts are, despite their terminological similarity, judged in different ways. The certain outcome option was perceived to be the most responsible choice both in the loss framed version and in the gain framed version, with or without outcome knowledge. Decision makers choosing the risky outcome option were accordingly perceived to be more blameworthy, especially when incurring a loss, but also in the no- outcome and positive outcome conditions. The risky decision maker was also expected to feel more personally involved, confirming the results of Experiment 1. Thus, "embracing chance" did not in this context absolve the actor from outcome blame and responsibility, as claimed by Tykocinski et al. (2016).

\section{Experiment 3: Saving and Losing Money versus Saving and Losing Lives}

The two scenarios used in Experiments 1 and 2 produced different patterns of preferences, as more participants preferred the risky option in Experiment 1 (life/death problem) than in Experiment 2 (financial problem). The pattern of responsibility ratings (R1 versus R2) was more similar. Experiment 3 explored the similarities and differences between the two domains by presenting both scenarios to the same participants. Results from the previous experiments suggested a difference between risking money and risking lives, but the two scenarios also differed in who would bear the consequences (self versus other). To make the scenarios more comparable, the financial decision makers in Experiment 3 handled a client's money rather than their own. Like the ministers of health, they were not causally involved in how the situation arose in the first place and did not have to bear the immediate consequences of their decisions.

The previous studies indicated that a risk- taking decision maker is given the same or higher outcome responsibility, even when being less in control of the outcome. Causality is regarded to be an integral part of outcome responsibility (Lagnado et al., 2013), although not the only one (Critchlow, 1985; Shaver \& Drown, 1986). In some research paradigms, like in the egocentric bias and shared responsibility literatures (Forsyth \& Kelley, 1994; Ross \& Sicoly, 1979; Teigen \& Brun, 2011), magnitude of causal contribution and degree of responsibility are used interchangeably. In the present experiment, ratings of causal contribution were included to assess the relationship between causality and outcome responsibility.

We believe that the concept of acting responsibly (R2) has strong normative connotations, reflecting the decision maker's moral and social accountability. In addition to blameworthiness, Experiment 3 also included ratings of "how acceptable are the choices" and "which option is easier to justify". These ratings were predicted to be higher for the certain option and would be positively related to R2 judgments.

\section{Method}

\section{Participants}

A total of 153 undergraduate students ( $64 \%$ women, mean age 24.2 years) from the University of Oslo participated as unpaid volunteers. They were randomly assigned to two conditions (save versus loss frame). 


\section{Materials and procedure}

The study was conducted as a $2 \times 2$ mixed design, with frame (save versus lose) as a between- groups, and choice (certain versus risky outcome) as a within- group factor. Participants were presented with two scenarios, the vaccination version of the AD problem used earlier and a modified version of the financial scenario to make the two scenarios as similar as possible.

The risky and riskless strategies were described as before. Participants were first asked which option they preferred themselves, then told about the choices made by the two protagonists, as in the previous experiments. Participants were asked how acceptable they found the choices to be, how responsible were the decision makers for the outcome (R1), how large were their contributions, how blameworthy were they, to which degree had they acted in a responsible way (R2), and finally, who would find it easier to give reasons for his/her choice. The order of $\mathrm{R} 1$ and $\mathrm{R} 2$ ratings was counterbalanced across participants. No order effect was found, so the ratings were pooled. Responses were assessed on 7- point scales (e.g., $1=$ no responsibility, 7 = fully responsible), except for the last question, which was a binary choice between which option (the certain versus the uncertain strategy) would be easier to explain.

\section{Results}

\section{Preferences}

As seen in Table $\underline{3}$, framing effects were observed for both scenarios, with the certain frame more strongly preferred in the save frame than the loss frame; $\chi^{2}(1, N=149)=4.81, p=.028$ for the finance scenario, and $\chi^{2}(1, N=147)=5.95, p=.015$ for the vaccination scenario, respectively.

Table 3. Percentage of participants in both frames preferring the two options, and judgments of which option is the easiest to explain for each scenario, Experiment 3

\begin{tabular}{ccc}
\multicolumn{2}{c}{ Save frame } & \multicolumn{2}{c}{ Loss frame } \\
Certain Risky & Certain Risky
\end{tabular}

Finance scenario

$\begin{array}{lllll}\text { Preference } & 79.5 \% & 20.5 \% & 63.2 \% & 36.8 \% \\ \text { Easiest to explain } & 93.0 \% & 7.0 \% & 84.2 \% & 15.8 \%\end{array}$

Vaccination scenario

$\begin{array}{lllll}\text { Preference } & 64.8 \% & 35.2 \% & 44.7 \% & 55.3 \% \\ \text { Easiest to explain } & 76.5 \% & 23.5 \% & 58.9 \% & 41.1 \%\end{array}$

Most participants felt that the certain option was easier to explain, but these answers were also affected by frame, as they believed it was easier to give reasons for the sure option in the positive than in the negative frame. Participants generally believed that the options they preferred themselves were easier to justify.

\section{Responsibility (R1) and causal contribution to outcome}


We find again that the decision makers were considered quite responsible in all conditions, even when making a risky choice. Responsibility ratings for finance and vaccination scenarios were compared in a 2 (Scenario: finance versus vaccination) $\times 2$ (Choice: certain versus uncertain outcome $) \times 2$ (Frame: loss versus save) mixed ANOVA, with frame as the between- subjects variable. This analysis revealed no main effects, but an interaction effect between scenario and choice, $F(1,137)=5.31, p<.023, \eta_{\mathrm{p}}^{2}=.04$. The actor choosing the certain option was perceived slightly less responsible for the outcome in the finance situation and slightly more in the vaccination situation.

A mixed ANOVA assessed the magnitude of causal contribution, showing a main effect of choice, $F(1,138)=6.71, p<.011, \eta_{\mathrm{p}}^{2}=.05$. The actor was perceived as more causal when choosing the certain outcome in both scenarios. No significant interaction of frame and choice was observed, nor of scenario and choice. Positive correlations were observed between magnitude of contribution and responsibility (R1) in all conditions and for both scenarios, with an average correlation (via Fisher's $r$ to $z$ transformation) of $r=.34$.

\section{Responsible behavior (R2), acceptability, and blame}

Decision makers choosing the certain outcome option were generally perceived to be acting in a more responsible way, as in the previous experiments. A mixed ANOVA was performed as above, but with acting responsibly (R2) as the dependent variable, demonstrating a main effect of choice, $F(1,140)=100.06, p<.001, \eta_{\mathrm{p}}^{2}=.42$. A significant interaction of choice and scenario was also observed, $F(1,140)=41.91, p<.001, \eta_{\mathrm{p}}^{2}=.15$, indicating that the certain option is considered more responsible in the finance than in the vaccination scenario. The same pattern of results was observed in both framing conditions.

R2 judgments were again related to the participants' own preferences, with a significant interaction between own preference and the decision makers' choice, both in the financial scenario, $F(1,145)=22.80, p<.001$, and in the vaccination scenario, $F(1,137)=60.76$, $p<.001$. A closer inspection revealed in the financial scenario, both sets of participants found the certain option to be a more responsible choice than the risky option, but the difference was again bigger for participants preferring the certain option $\left(M_{\text {certain }}=6.03 \mathrm{vs} M_{\text {risky }}=3.42\right.$, $t(105)=15.02, p<.001, d=1.49$ vs $M_{\text {certain }}=5.21$ vs $M_{\text {risky }}=4.28, t(42)=3.10, p=.003$, $d=0.48$ for risk preference). The vaccination scenario showed a similar pattern to Experiments 1 and 2, where participants preferring the certain option deemed the risky option to be particularly irresponsible $\left(M_{\text {certain }}=5.81 \mathrm{vs} M_{\text {risky }}=3.52, t(76)=9.81, p<.001\right.$, $d=1.12$ ). Participants preferring the risky option differed less in their R2 ratings of the two options $\left(M_{\text {certain }}=4.45\right.$ vs $\left.M_{\text {risky }}=5.00, t(63)=1.55, p=.047, d=-0.258\right)$.

Choosing the risky option was also rated to be less acceptable and more blameworthy, in all conditions, as shown in Table $\underline{4}$. An overall mixed ANOVA with acceptability as the dependent variable yielded a highly significant main effect of choice, $F(1,143)=63.62$, $p<.001, \eta_{\mathrm{p}}^{2}=.31$. The difference was especially pronounced in the finance situation, demonstrated by a significant interaction effect of scenario and choice, $F(1,143)=9.92$, $p<.002, \eta_{\mathrm{p}}{ }^{2}=.065$. Choosing the risky option is less acceptable in the save frame than in the loss frame $\left(F(1,143)=6.24, p<.014, \eta_{\mathrm{p}}{ }^{2}=.04\right)$. Parallel results were obtained for blameworthiness.

Table 4. Mean ratings (SD) for certain and risky options for saving and losing money (upper panel) and saving and losing lives (lower panel), Experiment 3 


\begin{tabular}{|c|c|c|c|c|}
\hline \multirow[b]{2}{*}{ Ratings } & \multicolumn{2}{|c|}{ Positive frame } & \multicolumn{2}{|c|}{ Negative frame } \\
\hline & Certain & Risky & Certain & Risky \\
\hline \multicolumn{5}{|l|}{ Finance scenario } \\
\hline Responsibility 1 (SD) & $4.97(1.68)$ & $5.29(1.52)-1.88$ & $5.09(1.75)$ & $5.20(1.50)-0.44$ \\
\hline Causal contribution (SD) & $4.71(1.76)$ & 4.17 (1.60) 1.82 & $4.96(1.67)$ & 4.38 (1.39) $2.20_{-}^{*}$ \\
\hline Responsibility 2 (SD) & $5.97(1.18)$ & 3.66 (1.28) $10.38 * * *$ & $5.57(1.40)$ & 3.68 (1.38) $7.99 * * *$ \\
\hline Acceptability (SD) & $5.83(1.14)$ & 4.04 (1.38) 8.97*** & $5.23(1.37)$ & 4.17 (1.33) 4.88 **** \\
\hline Blame (SD) & $2.88(1.42)$ & $4.79(1.51)-8.28$ *** & $3.53(1.64)$ & $4.43(1.42)-3.76$ *** \\
\hline \multicolumn{5}{|l|}{ Vaccination scenario } \\
\hline Responsibility 1 (SD) & $5.21(1.67)$ & 5.07 (1.85) 0.52 & $5.26(1.67)$ & 4.89 (1.68) 1.58 \\
\hline Causal contribution (SD) & $4.60(1.88)$ & 4.37 (1.75) 0.90 & $4.93(1.78)$ & 4.55 (1.44) 1.41 \\
\hline Responsibility 2 (SD) & $5.38(1.49)$ & 4.14 (1.56) 4.00*** & $5.01(1.64)$ & $4.21(1.41) 2.78 * *$ \\
\hline Acceptability (SD) & $5.01(1.55)$ & 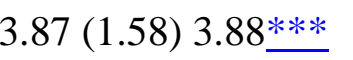 & 4.88 (1.69) & $4.41(1.49) 1.81$ \\
\hline Blame (SD) & $3.61(1.73)$ & $4.80(1.56)-4.16^{* * * *}$ & $3.75(1.57)$ & $4.42(1.39)-2.49 *$ \\
\hline
\end{tabular}

The close correspondence between R2, acceptability, and blameworthiness was confirmed by examining the correlations between these variables. Acting responsibly (R2) ratings correlated positively with acceptability ratings, for both scenarios and in all conditions, with a mean $r=.62$, and negatively with blameworthiness, with a mean $r=-.43$ (both means are based on eight correlations, averaged after Fisher's $r$ to $z$ transformations).

To summarize, we show in Figure 1 that decision makers were in all conditions viewed as equally responsible for outcome, regardless of the risks taken. In contrast, risky decisions were viewed as much less responsible acts. 


$$
6
$$

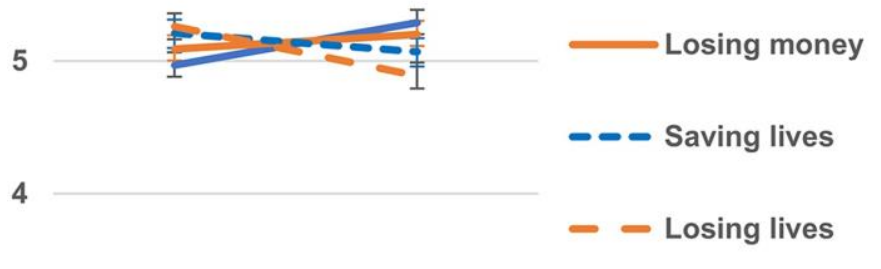

3

Certain Risky
Saving money

Losing money

- Losing lives
6

5

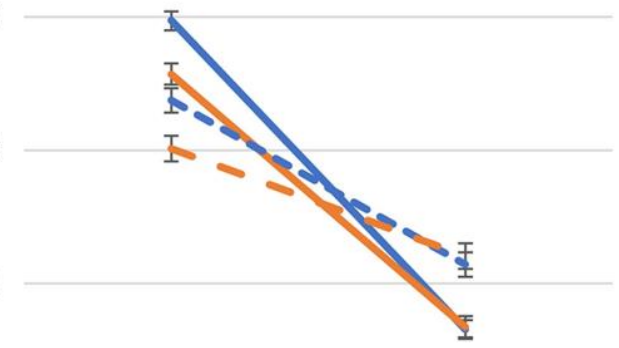

Certain Risky

Figure 1 Mean responsibility judgments with standard errors for decision makers choosing certain and risky options, in two positively and negatively framed risky choice scenarios, Experiment 3.

\section{Discussion}

Framing effects were demonstrated for own choice both in the finance and in the vaccination scenario. The risky option was more attractive in the vaccination situation than in the finance scenario. Frames did also to some extent influence which decision participants found it easier to justify.

We observed again a dissociation between R1 and R2 ratings, as demonstrated in Figure 1 . The certain choice was perceived to be a more responsible course of action (R2) in all conditions. It was also more acceptable, less blameworthy, and easier to justify, confirming the idea that acting responsibly is about "doing the right thing for the right reasons" (Anderson, 1995) and that making riskless choices is the normatively right thing to do, although less so when lives are at stake.

To be held personally responsible (R1) for an outcome was, as expected, related to the magnitude of the causal contribution. This contribution was larger for the decision maker who chose the certain option, and yet we see again that choosing an uncertain option does not absolve the decision maker from outcome responsibility.

Results from all three experiments strongly suggest that knowledge about the risks one is taking is sufficient to make risk- takers responsible for outcomes they cannot completely foresee or control.

\section{Experiment 4: Saving Lives by Uninformed and Informed Decision Makers}


The previously mentioned results appear to contradict Leonhardt et al.'s (2011) and Tykocinski et al.'s (2016) claims that risk- taking reduces outcome responsibility of the decision maker, because of the chance factors involved. We found risk- takers in these studies to be rated equally or more responsible, perhaps because they were considered knowledgeable about the risk and were choosing it voluntarily. An additional study was performed to contrast informed with uninformed decision makers who are running the same risks without deliberately choosing them. Under these circumstances, responsibility might be reduced, simply because the actors cannot foresee the results or the amounts of risk involved.

The previous studies have included decision- making dilemmas involving finance and life and death situations, framed positively and negatively, and with different outcomes, demonstrating comparable patterns of results. In this experiment, we use only one decision problem, one frame (saving, rather than losing lives), and only one (negative) outcome of the risky option.

\section{Method}

\section{Participants}

A total of 132 undergraduate students (66\% women, mean age 22.6 years) from the University of Oslo participated. They were randomly assigned to two conditions (informed versus uninformed actors).

\section{Materials and procedure}

Both groups were presented with the vaccination scenario, similarly as in the other studies. However, participants in the uninformed group were told that the research report describing the effect of the two vaccines was not ready at the time of the decision, but would be available later. Both groups were informed about the outcomes. In Country A, 200 people were saved, as expected. In Country B, none of the 600 was saved.

Participants were asked to rate each decision maker's responsibility for the outcome (R1), how acceptable was the decision, how large was the decision maker's causal contribution to the outcome, and how responsible was the decision maker's choice (R2), on 1-7 rating scales, as before.

\section{Results}

\section{Responsibility (R1) and causal contribution to outcome}

A $2 \times 2$ mixed ANOVA with condition (between- Ss) and choice (within- Ss) as the two factors showed a main effect of condition, $F(1,131)=19.43, p<.001, \eta_{\mathrm{p}}{ }^{2}=.13$, where the uninformed ministers were rated lower in outcome responsibility than the informed ministers. Yet, there was no effect of choice, $F(1,131)=1.40, p<.001, \eta_{\mathrm{p}}{ }^{2}=.01$, so both ministers were judged to carry the same responsibility (R1) for the outcome regardless of choosing the certain option or the risky option. There was no interaction between condition and choice, $F(1,131)=0.19, p=.66, \eta_{\mathrm{p}}^{2}=.001$. As seen in Table $\underline{5}$, the informed risk- taking minister was rated as having less causal contribution to the outcome, compared with the minister who chose the certain program. Thus, being uninformed reduces responsibility, but taking a risk does not reduce decision makers' responsibility, even if their causal contributions are reduced. 
Table 5. Mean ratings of certain and risky options for saving lives for informed and uninformed decision makers, Experiment 4

\section{Uninformed decision makers Informed decision makers}

$\begin{array}{lcccccc} & \text { Certain } & \text { Risky } & \boldsymbol{t} & \text { Certain } & \text { Risky } & \boldsymbol{t} \\ \text { Responsibility 1 (SD) } & 3.82(1.81) & 3.59(1.74) & 1.26 & 4.93(1.65) & 4.82(1.72) .49 \\ \text { Causal contribution (SD) } & 4.33(1.92) & 4.08(1.79) & .56 & 4.72(1.77) & 3.94(1.82) & 3.27 * \\ \text { Responsibility 2 (SD) } & 4.79(1.61) & 4.80(1.60) & .48 & 5.39(1.04) & 4.30(1.28) & 5.09 * * * \\ \text { Acceptability (SD) } & 5.03(1.31) & 5.11(1.43) & -.37 & 5.33(1.72) & 4.70(1.53) & 3.49 * *\end{array}$

- $* p<.05$.

- $* * p<.01$.

- $* * * p<.001$ (paired samples t- tests).

\section{Responsible behavior (R2) and acceptability}

Table $\underline{5}$ indicates that the informed minister of health who chose the certain option made a more acceptable decision and acted in a more responsible way (R2) than his risk- taking colleague. This was confirmed in a $2 \times 2$ mixed ANOVA with condition (between- Ss) and choice (within- Ss) as the two factors showed an interaction of condition and choice, $\left.F(1,130)=11.50, p<.001, \eta_{\mathrm{p}}{ }^{2}=.08\right)$. There was also an interaction between choice and condition for ratings of acceptability, $F(1,131)=6.71, p=.011, \eta_{\mathrm{p}}{ }^{2}=.05$, showing that the informed minister of health and based on this knowledge chose the certain option, made a more acceptable decision.

\section{Discussion}

Responsibility appeared in this experiment to be much closer related to the actors' state of knowledge at the time of making the decision than to their ability of controlling the result. Following the distinction between internal (epistemic) uncertainty, that is, uncertainty that springs from ignorance and incomplete knowledge, and external (aleatory) uncertainty, which depends on outcome variability due to random processes in the outside world (Kahneman \& Tversky, 1982), we might conclude that responsibility judgments are more influenced by internal uncertainty than of external uncertainty. In line with this, we often hear accountable decision makers, like politicians and chief executive officer of companies, excuse themselves from responsibility by declaring themselves uninformed. They rarely say they have no responsibility because they left the outcome to chance, as they may intuitively realize that such behavior would be blameworthy and make them appear as "negligent" or irresponsible decision makers. Choosing the risky option will at best only reduce one's own feeling of responsibility, not the overall responsibility as perceived by an external judge.

\section{General Discussion}

The present set of studies investigated whether judgments of responsibility differ between certain and risky options, distinguishing between responsibility for the outcome (R1) and acting responsibly (R2). Participants were asked to compare decision makers who had chosen the certain and the risky options in two domains and to assess their perceived degree of responsibility and other related concepts. In Experiment 1, R1 and R2 ratings were performed by different participants (between- Ss design), whereas in Experiments 2-4, both ratings were 
performed by the same individuals (within- Ss designs). Potential framing effects were studied in Experiments 1, 2, and 3 (as between- Ss factors). Experiment 2 also included post- outcome conditions, allowing participants to rate the decision makers' responsibilities after the outcomes of their choices were known. Experiment 4 differed from the other studies by comparing informed with uninformed decision makers, who at the time of the decision lack knowledge of the risks involved.

In all four experiments, ratings of outcome responsibility (R1) were quite high in all conditions. Those who chose the risky option were not excused from responsibility, despite being less in control and making a smaller causal contribution, which are two of the key premises for being held responsible (Fischer \& Ravizza, 1998; Hart, 2008; Heider, 1958; Shaver, 1985; Weiner, 1995). Besides, the risky decision was an informed choice and freely chosen, leaving both potential outcomes foreseeable and known.

Choosing the certain program was, as predicted, generally regarded as the most responsible thing to do (R2). In line with this, it was also regarded as a more acceptable and less blameworthy choice, and easier to justify than the risky option. Risky decision makers were, however, viewed as more involved, suggesting that risk- taking is a norm violating action, which comes with a personal cost for the decision maker (Nichols, 2002).

We thus observed a difference between R1 and R2 judgments, confirming an important distinction introduced by Nordbye and Teigen (2014a) between responsibility for outcomes and responsible acts. Despite the similarity in terms, having the responsibility for an outcome (R1) and behaving in a responsible way (R2) involve two different interpretations of responsibility. A "responsible" (R2) decision maker will behave according to social obligations, professional requirements, and moral maxims like "be considerate" and "do not expose others to harm". Role expectations may require that "responsible" leaders also accept outcome responsibility (R1) for events that they did not actively produce but allowed to happen (or perhaps "should have foreseen").

\section{Responsibility aversion}

It has been suggested that choosing the risky option in the loss frame is a way of strategically managing impression formation in order to avoid blame (Leonhardt et al., 2011; Tykocinski et al., 2016). We were not able to confirm previous findings of lower "risk of responsibility" and less blame for the risk- taker in the AD paradigm. Overall, we find that decisions leaving parts of the outcome to chance give decision makers equal or even more, rather than less, outcome responsibility, making risk a poor strategy for evading responsibility. Risky decisions may draw attention to the actors' freedom of choice, accompanied by a heightened sense of personal agency, which in turn increases responsibility attributions (Lagnado et al., 2013). In choosing the risky option, the decision maker is pivotal in affecting the outcome, thus implying outcome responsibility, despite the uncertainties involved.

In our experiments, participants were asked to judge the responsibility of the decision makers as seen from an external perspective (how responsible is the decision maker for the outcome), whereas Leonhardt et al. (2011) asked how the participants themselves would have felt about the choice. To check the effect of perspective, we ran an additional control study, where participants $(N=194)$ received the positively framed versions of both scenarios either formulated in objective terms: "who is more responsible", or in terms of the decision makers' subjective feelings: "who will feel more responsible". However, these divergent formulations 
did not make a difference. Risk takers in both groups were found to have more outcome responsibility than those who chose the riskless option. Some of Leonhardt et al.'s (2011) studies involved loss-loss situations. In such situations, a negative outcome (e.g., a town will be hit by a stray missile) will occur regardless of the decision maker's actions. In such cases, feeling better about an uncertain option (the town hit by the missile is random) compared with the certain option (you decide which town will be hit by the missile) might reflect decision aversion (Beattie, Baron, Hershey, \& Spranca, 1994) rather than responsibility aversion.

A reduction in outcome responsibility (R1) was only found for uninformed decision makers (Experiment 4). Pleading lack of knowledge may be a way for accountable decision makers to excuse themselves from responsibility, however, trying to evade responsibility by leaving the outcome up to chance does not seem to lead to absolution. On the contrary, it can backfire by being regarded as irresponsible and blameworthy behaviors.

Across all experiments, the risky choice was judged to be less responsible. R2 judgments were also related to participants' preferences. Participants who preferred the certain option rated the risky option as substantially less responsible than the certain option, while participants preferring the risky option differed comparatively little in their R2 ratings of the two options. The present findings therefore suggest a somewhat different story: a decision maker who chooses the risky option will be judged rather harshly by people who themselves prefer the certain option, while people preferring the risky option will find the decision to be equally responsible (R2) as choosing the certain option. A similar pattern was also found for blame ratings, indicating that the certain option may often be the "safest" option. A moral echoing effect has recently been suggested, where people's judgments of moral responsibility seem to echo their framing preferences in the classical AD task (Parkinson \& Byrne, 2017). Though moral responsibility is not synonymous to acting responsibly (one can be morally responsible for outcomes, not just acts), Parkinson and Byrne's findings are compatible with ours.

The effect of preference on responsibility (R2) ratings also indicates that riskless choices are not in and by themselves more responsible; they are responsible decisions only if decision makers think they are wise. Thus, risk- takers were viewed as behaving more responsibly in matters of life and death (trying to save all and lose none) than in a financial dilemma, where saving at least some of the money seem better than risking it all. Taken together, the findings suggest that decision makers seeking to manage others' opinions of them and their decisions should carefully examine both the nature and domain of the choices they make.

\section{Responsibility and related concepts}

Another possible reason for the diverging findings may be sought in the operationalizations of the concept of responsibility (for a discussion, see Nordbye, 2015). Even though the present studies found the risky choice to involve less control and less contribution to the outcome, we did not find a reduction in responsibility or blame. Responsibility has long been recognized as an ambiguous concept (Fincham \& Jaspars, 1980; Hamilton \& Sanders, 1981; Hart, 2008; Sousa, 2009). Both the scientific and everyday use of the term is prone to idiosyncratic differences (e.g., Malle et al., 2014). For example, attribution literature often equates responsibility either with causality (e.g., Harvey \& Rule, 1978; Lagnado et al., 2013), or with blame (e.g., Shultz, Schleifer, \& Altman, 1981). The present research confirms that these concepts are related to two quite different aspects of the responsibility compound. Moreover, blameworthiness can be directed toward the action (as in R2) or outcome (as in R1). In 
Leonhardt et al.'s study, participants (between- Ss) were asked how strongly the outcome would make them feel accountable, how guilty they would feel, and how much they would blame themselves (the term responsibility was not used). But the outcomes were not disclosed, and some participants in the "uncertain" condition might well have thought that the program had been successful and nobody died. With such a lucky outcome, they would have little reason for blaming themselves.

?A3B2 twb $=.35 \mathrm{w}$ ? > Responsibility is not just essential for blaming others, it is also crucial when it comes to blaming oneself. Self- blame is an essential component of regret, and it has been suggested that responsibility is a precondition for regret (Zeelenberg, van Dijk, \& Manstead, 1998). In their decision justification theory, Connolly and Zeelenberg (2002) distinguish between process regret (self- blame for having made a poor choice) and outcome regret (associated with having obtained a comparatively poor outcome). Evidently, the first kind of regret pertains to the act of choosing, irrespective of outcome, and is accordingly related to having acted in a less responsible way (R2 in our terminology). A study relating these two facets of regret to the two kinds of responsibility judgment discussed in the present work might provide additional insights in the assessment of decision making under uncertainty.

The distinction between a focus on process and a focus on outcome is central in several related fields. Within the management literature, studies have investigated the effects of holding decision makers accountable for the quality of their efforts (process accountability) or for their effectiveness in actually delivering outcomes (outcome accountability) (for an overview, see Patil, Vieider, \& Tetlock, 2014). The distinction bears resemblance to the two responsibility concepts discussed in the present paper. However, different forms of accountability are typically seen as situational characteristics that can be manipulated by an experimenter to induce various behavioral effects. For instance, an emphasis on procedural accountability has been found to encourage a more thorough evaluation of available information, whereas focus on outcome accountability may hamper judgments (SiegelJacobs \& Yates, 1996). In contrast, the present studies have compared how decision makers' responsibilities for their actions and outcomes will be evaluated. Future studies should investigate whether outcome accountable managers also will be judged more responsible for outcomes (R1) and, correspondingly, whether actors who are held process accountable will be evaluated as behaving in a more responsible way (R2).

\section{Responsibility and framing}

While the classical framing effects were replicated in participants' preferences, which in turn affected ratings of acting responsibly (R2) and blameworthiness, both frames produced rather similar response patterns for ratings of responsibility, personal involvement, and causal contribution, indicating that the different evaluations of the risky and the riskless options are robust and not uniquely dependent on one particular frame or one particular domain. The studies of Tykocinski et al. (2016) demonstrate that degree of responsibility can amplify the framing effect. Under high responsibility, more people choose the risky options when framed as losses rather than as gains. But it does not follow that choice of risky option will reduce responsibility. What they show is that responsibility affects some choices, which, however, does not imply that other choices will take responsibility away. Thus, we do not dispute Tykocinski's data but disagree with the conclusions they draw. 
Framing effects of responsibility judgments have previously been observed for opponents competing for the world championship in chess (Nordbye \& Teigen, 2014b), but this study focused on causal responsibility and did not involve risks or moral evaluations. Moreover, it may be easier to transfer the responsibility from one actor to another, as in the chess study, than from one human decision maker to the arbitrary interventions of good and bad luck. After all, responsibility is a human prerogative and not easily taken over by chance.

\section{Biographies}

- Gro Hege Haraldsen Nordbye holds her PhD from the University of Oslo and is Leader for HMS and HR in Veidekke, a Scandinavian entrepreneurial company. Her research interests include decision making, responsibility, and moral judgments.

- Anine H. Riege is a postdoctoral researcher at Kingston Business School in London. Her research interests include responsibility, probability judgments, numeracy, and emotions and decision making.

- Karl Halvor Teigen is professor emeritus at the University of Oslo and adjunct research scientist at Simula Research Laboratory, Norway. His research interests include social cognition, probability judgments, and communication of uncertainty.

\section{References}

- Alicke, M. D. (2000). Culpable control and the psychology of blame. Psychological Bulletin, 126(4), 556-574. https://doi-org.ezproxy.uio.no/10.1037//00332909.126.4.556.

- Anderson, S. L. (1995). Being morally responsible for an action versus acting responsibly or irresponsibly. Journal of Philosophical Research, 20, 451-462.

- Beattie, J., Baron, J., Hershey, J. C., \& Spranca, M. D. (1994). Psychological determinants of decision attitude. Journal of Behavioral Decision Making, 7(2), 129144. https://doi-org.ezproxy.uio.no/10.1002/bdm.3960070206.

- Cane, P. (2002). Responsibility in law and morality. Oxford, UK: Hart Publishing.

- Chockler, H., \& Halpern, J. Y. (2004). Responsibility and blame: A structural- model approach. Journal of Artificial Intelligence Research, 22, 93-115.

- Connolly, T., \& Zeelenberg, M. (2002). Regret in decision making. Current Directions in Psychological Science, 11(6), 212-216. https://doiorg.ezproxy.uio.no/10.1111/1467- 8721.00203.

- Critchlow, B. (1985). The blame in the bottle-Attributions about drunken behavior. Personality and Social Psychology Bulletin, 11(3), 258-274. https://doiorg.ezproxy.uio.no/10.1177/0146167285113003.

- Druckman, J. N., \& McDermott, R. (2008). Emotion and the framing of risky choice. Political Behavior, 30(3), 297-321. https://doi-org.ezproxy.uio.no/10.1007/s11109008- 9056- y.

- Fagley, N. S., \& Miller, P. M. (1997). Framing effects and arenas of choice: Your money or your life? Organizational Behavior and Human Decision Processes, 71(3), 355-373. https://doi-org.ezproxy.uio.no/10.1006/obhd.1997.2725. 
- Fincham, F., \& Jaspars, J. (1980). Attribution of responsibility: From man the scientist to man as lawyer. In B. Leonard (Ed.), Advances in Experimental Social Psychology ( Vol. 13, pp. 81-138). Academic Press.

- Fischer, J. M., \& Ravizza, M. (1998). Responsibility and control: A theory of moral responsibility. Cambridge University Press.

- Forsyth, D. R., \& Kelley, K. N. (1994). Attribution in groups-Estimations of personal contributions to collective endeavors. Small Group Research, 25(3), 367383. https://doi-org.ezproxy.uio.no/10.1177/1046496494253002.

- Hamilton, V. L., \& Hagiwara, S. (1992). Roles, responsibility, and accounts across cultures. International Journal of Psychology, 27(2), 157-179. https://doiorg.ezproxy.uio.no/10.1080/00207599208246873.

- Hamilton, V. L., \& Sanders, J. (1981). The effect of roles and deeds on responsibility judgments - The normative structure of wrongdoing. Social Psychology Quarterly, 44(3), 237-254. https://doi-org.ezproxy.uio.no/10.2307/3033836.

- Hart, H. L. A. (2008). Punishment and responsibility: Essays in the philosophy of law. Oxford University Press.

- Harvey, M. D., \& Rule, B. G. (1978). Moral evaluations and judgments of responsibility. Personality and Social Psychology Bulletin, 4(4), 583-588. https://doiorg.ezproxy.uio.no/10.1177/014616727800400418.

- Heider, F. (1958). The psychology of interpersonal relations. New York: Wiley.

- Kahneman, D., \& Tversky, A. (1979). Prospect theory-An analysis of decision under risk. Econometrica, 47(2), 263-291.

- Kahneman, D., \& Tversky, A. (1982). The psychology of preferences. Scientific American, 246(1), 160.

- Keren, G., \& Teigen, K. H. (2010). Decisions by coin toss: Inappropriate but fair. Judgment and Decision making, 5(2), 83-101.

- Kirkebøen, G., \& Nordbye, G. H. H. (2015). Intuitive choices intensify emotional experiences: An overlooked reason for the "intuition bias"? In G. H. H. Nordbye (Ed.), Judgment of responsibility: Agency, morality and risk. Oslo: Faculty of Social Sciences, University of Oslo.

- Kühberger, A. (1995). The framing of decisions-A new look at old problems. Organizational Behavior and Human Decision Processes, 62(2), 230-240. https://doiorg.ezproxy.uio.no/10.1006/obhd.1995.1046.

- Kühberger, A., Schulte- Mecklenbeck, M., \& Perner, J. (1999). The effects of framing, reflection, probability, and payoff on risk preference in choice tasks. Organizational Behavior and Human Decision Processes, 78(3), 204-231. https://doiorg.ezproxy.uio.no/10.1006/obhd.1999.2830.

- Lagnado, D. A., \& Channon, S. (2008). Judgments of cause and blame: The effects of intentionality and foreseeability. Cognition, 108(3), 754-770. https://doiorg.ezproxy.uio.no/10.1016/j.cognition.2008.06.009.

- Lagnado, D. A., Gerstenberg, T., \& Zultan, R. i. (2013). Causal responsibility and counterfactuals. Cognitive Science, 37(6), 1036-1073. https://doiorg.ezproxy.uio.no/10.1111/cogs.12054.

- Leonhardt, J. M., Keller, L. R., \& Pechmann, C. (2011). Avoiding the risk of responsibility by seeking uncertainty: Responsibility aversion and preference for indirect agency when choosing for others. Journal of Consumer Psychology, 21(4), 405-413. https://doi-org.ezproxy.uio.no/10.1016/j.jcps.2011.01.001.

- Malle, B. F., Guglielmo, S., \& Monroe, A. E. (2014). A theory of blame. Psychological Inquiry, 25(2), 147-186. https://doiorg.ezproxy.uio.no/10.1080/1047840x.2014.877340. 
- Mandel, D. R. (2014). Do framing effects reveal irrational choice? Journal of Experimental Psychology- General, 143(3), 1185-1198. https://doiorg.ezproxy.uio.no/10.1037/a0034207.

- Mandel, D. R. (2015). Communicating numeric quantities in context: implications for decision science and rationality claims. Frontiers in Psychology, 6, 4. https://doiorg.ezproxy.uio.no/10.3389/fpsyg.2015.00537.

- Mazzocco, P. J., Alicke, M. D., \& Davis, T. L. (2004). On the robustness of outcome bias: No constraint by prior culpability. Basic and Applied Social Psychology, 26(23), 131-146. https://doi-org.ezproxy.uio.no/10.1207/s15324834basp2602\&3 3.

- Nichols, S. (2002). Norms with feeling: Towards a psychological account of moral judgment. Cognition, 84(2), 221-236. https://doi-org.ezproxy.uio.no/10.1016/s00100277(02)00048- 3.

- Nordbye, G. H. H. (2015). Judgment of responsibility: agency, morality and risk. (no. 525), Department of Psychology, Faculty of Social Sciences, University of Oslo, Oslo.

- Nordbye, G. H. H., \& Teigen, K. H. (2014a). Being responsible versus acting responsibly: Effects of agency and risk taking on responsibility judgments. Scandinavian Journal of Psychology, 55(2), 102-114. https://doiorg.ezproxy.uio.no/10.1111/sjop.12111.

- Nordbye, G. H. H., \& Teigen, K. H. (2014b). Responsibility judgments of wins and losses in the 2013 Chess Championship. Judgment and Decision making, 9(4), 335348.

- Parkinson, M., \& Byrne, R. M. J. (2017). Moral judgments of risky choices: A moral echoing effect. Judgment and Decision making, 12(3), 236-252.

- Patil, S. V., Vieider, F. M., \& Tetlock, P. E. (2014). Process and outcome accountability. In M. Bovens, R. E. Goodin, \& T. Schillemans (Eds.), The Oxford handbook of public accountability. Oxford University Press.

- Robbennolt, J. K. (2000). Outcome severity and judgments of "responsibility": A meta- analytic review. Journal of Applied Social Psychology, 30(12), 2575-2609. https://doi-org.ezproxy.uio.no/10.1111/j.1559- 1816.2000.tb02451.x.

- Ross, M., \& Sicoly, F. (1979). Egocentric biases in availability and attribution. Journal of Personality and Social Psychology, 37(3), 322-336.

- Schwarz, N. (1999). Self- reports: How the questions shape the answers. American Psychologist, 54(2), 93-105. doi:citeulike- article- id:815325

- Shaver, K. G. (1985). The attribution of blame: Causality, responsibility, and blameworthiness. New York: Springer.

- Shaver, K. G., \& Drown, D. (1986). On causality, responsibility, and self- blame: A theoretical note. Journal of Personality and Social Psychology, 50(4), 697-702.

- Shultz, T. R., Schleifer, M., \& Altman, I. (1981). Judgments of causation, responsibility, and punishment in cases of harm- doing. Canadian Journal of Behavioural Science - Revue Canadienne Des Sciences Du Comportement, 13(3), 238-253. https://doi-org.ezproxy.uio.no/10.1037/h0081183.

- Siegel- Jacobs, K., \& Yates, J. F. (1996). Effects of procedural and outcome accountability on judgment quality. Organizational Behavior and Human Decision Processes, 65(1), 1-17. https://doi-org.ezproxy.uio.no/10.1006/obhd.1996.0001.

- Sousa, P. (2009). A cognitive approach to moral responsibility: The case of a failed attempt to kill. Journal of Cognition and Culture, 9(3), 171-194. https://doiorg.ezproxy.uio.no/10.1163/156770909X12489459066183.

- Stone, E. R., Choi, Y. S., de Bruin, W. B., \& Mandel, D. R. (2013). I can take the risk, but you should be safe: Self- other differences in situations involving physical safety. Judgment and Decision making, 8(3), 250-267. 
- Teigen, K. H., \& Brun, W. (2011). Responsibility is divisible by two, but not by three or four: Judgments of responsibility in dyads and groups. Social Cognition, 29(1), 1542.

- Teigen, K. H., \& Nikolaisen, M. I. (2009). Incorrect estimates and false reports: How framing modifies truth. Thinking \& Reasoning, 15(3), 268-293. https://doiorg.ezproxy.uio.no/10.1080/13546780903020999.

- Tversky, A., \& Kahneman, D. (1981). The framing of decisions and the psychology of choice. Science, 211(4481), 453-458.

- Tykocinski, O. E., Amir, I., \& Ayal, S. (2016). Embracing chance tactically: A different perspective on risk taking. Journal of Behavioral Decision Making, n/a- n/a. doi:https://doi-org.ezproxy.uio.no/10.1002/bdm.1981

- Vincent, N. A. (2011). A structured taxonomy of responsibility concepts. In N. A. Vincent, I. v. d. Poel, \& J. v. d. Hoven (Eds.), Moral responsibility: Beyond free will and determinism (pp. 15-35). New York: Springer- Verlag.

- Walster, E. (1966). Assignment of responsibility for an accident. Journal of Personality and Social Psychology, 3(1), 73. https://doiorg.ezproxy.uio.no/10.1037/h0022733.

- Wang, X. T. (1996). Domain- specific rationality in human choices: Violations of utility axioms and social contexts. Cognition, 60(1), 31-63. https://doiorg.ezproxy.uio.no/10.1016/0010- 0277(95)00700- 8 .

- Weiner, B. (1995). Judgments of responsibility: A foundation for a theory of social conduct. New York: Guilford Press.

- Zeelenberg, M., van Dijk, W. W., \& Manstead, A. S. R. (1998). Reconsidering the relation between regret and responsibility. Organizational Behavior and Human Decision Processes, 74(3), 254-272. https://doiorg.ezproxy.uio.no/10.1006/obhd.1998.2780.

- Zimmermann, M. J. (1987). Luck and moral responsibility. In D. Statman (Ed.), Moral luck (pp. 217-234). New York: State University of New York Press. 